\title{
Militância política e relações de gênero: o caso das mulheres militantes no Curdistão*
}

\author{
Lucia Amorosi**
}

\section{Resumo}

Este artigo pretende analisar a participação feminina atual na luta curda pela independência e contra o fundamentalismo do Estado Islâmico, a fim de demonstrar como ela gerou uma mudança radical nas relações sociais entre os sexos. Essa questão principal foi abordada através da promoção de uma nova imagem da mulher e do seu papel social que não era mais só aquilo de mãe $e$ esposa. Depois de uma breve visão geral sobre a complexa história de povo curdo e, consequentemente, do papel que as mulheres têm desempenhado dentro dela, tentei retomar a evolução teórica da desconstrução do gênero, com o objetivo de destacar a permeabilidade do conceito em relação ao contexto histórico e social. Além disso, tenho analisado a relação entre gênero e a constituição da ideia de nação, a partir do conceito de genderification do nacionalismo. Por fim, considerando a especificidade das mulheres curdas como mulheres subjugadas, subalternas e sem nacionalidade reconhecida, é abordada uma definição das interconexões teóricas entre gênero, raça, etnia $e$ classe, a fim de contextualizar essa realidade peculiar.

Palavras-chave: Gênero, Militância, Identidade, Curdistão.

\footnotetext{
" Recebido em 03 de julho de 2016, aceito em 07 de fevereiro de 2019.

** Doutoranda em Sociologia Econômica na Universidade de Milão, Milão, Itália. Lucia.Amorosi@unimi.it / https://orcid.org/0000-0002-0332-2772 
Political Activism and Gender Relations:

The Case of Militant Women in Kurdistan

\begin{abstract}
This paper analyzes current female participation in the Kurdish struggle for independence and against the fundamentalism of the Islamic State, to demonstrate how it has generated a radical change in social relations between genders. This main issue was addressed through the promotion of a new image of women and their social roles, which had previously been nothing more than mother and wife. After a brief overview of the complex history of the Kurdish people and of the role women have played within it, I reviewed the theoretical evolution of the deconstruction of gender, to highlight the permeability of the concept in relation to historical and social contexts. I also analyzed the link between gender and the constitution of the idea of nation, based on the concept of genderification of nationalism. Finally, considering the specificity of Kurdish women as subjugated, subaltern women without recognized nationality, a definition of the theoretical interconnections between gender, class, race and ethnicity is approached, to contextualize this peculiar reality.
\end{abstract}

Keywords: Gender, Kurdistan, Identity, Militancy. 


\section{Introdução}

Nos últimos anos, a mídia ocidental tem apresentado à opinião pública europeia a imagem das mulheres curdas combatentes engajadas na luta contra o Estado Islâmico na área síria marcada por um profundo caos político e institucional desde 2012. A Europa, portanto, tem podido descobrir a existência dessas mulheres e construir sobre elas um mito, que já foi significativamente manipulado pela representação de sua luta como orientada exclusivamente para a proteção do povo curdo, através da limitação do avanço do Estado Islâmico. Na verdade, esse protagonismo das mulheres não é determinado exclusivamente pela oposição aos fundamentalistas, enquanto inscreve-se na longa luta de emancipação do povo curdo que, além das aspirações independentistas e autonomistas, caracterizase pelas fortes reivindicações anticapitalistas e antisexistas. Nesse sentido, a escolha das primeiras pioneiras de se juntar à luta armada, a partir de 1978, constitui um exemplo para muitas outras curdas e determinou a concretização de um protagonismo feminino, tão enraizado que conseguiu transcender o nível militar para se estruturar também em nível político-social e das relações interpessoais.

Este trabalho tenciona demonstrar como o papel das mulheres no processo de emancipação e libertação do povo curdo constituiu uma contribuição determinante para esse processo, tanto a nível prático como teórico. Nessa perspectiva foi a experiência concreta da cotidianidade da luta armada pela emancipação (hoje reiterada no combate contra Daesh) ${ }^{1}$ que permitiu que tanto as mulheres como os homens chegassem a questionar algumas noções e ideias sobre as relações sociais entre os sexos, até então aceitas acriticamente. Pois esse protagonismo feminino foi reconhecido e discutido apenas recentemente, este artigo tenta analisar e esclarecer as questões principais envolvidas

\footnotetext{
1 Expressão literal não traduzida do autodenominado Estado Islâmico.
} 
em este tema por meio de algumas contribuições teóricas relevantes no campo dos estudos de gênero.

Embora, às vezes, a vontade de favorecer a compreensão teórica desse fenômeno pode tê-lo reduzido a um mero objeto de estudo, não existe alguma intenção de constringi-lo dentro dos limites de uma abordagem puramente teórico-conceitual, enquanto a sua importância fundamental reside precisamente nas mudanças concretas que conseguiu gerar.

\section{Mulheres e luta armada no Curdistão}

Para poder compreender o papel das mulheres curdas no processo de mudança política e social do próprio povo, é preciso esclarecer brevemente o seu contexto histórico. Esse povo, em sua maioria muçulmano sunita, que fala a sua própria língua e tem uma identidade étnica muito forte, fazia parte do mosaico étnico do Império Otomano. Após a derrota sofrida durante a Primeira Guerra Mundial, e com o Tratado de Lausana, de 1923,que estabeleceu as fronteiras das nações nascidas a partir das ruínas do antigo império, o território foi dividido entre Iraque, Irã, Turquia e Síria. Apesar disso, foi só em 1978 que o independentismo curdo alcançou uma dimensão mais estruturada e reivindicativa através do $\mathrm{PKK}$, o Partido dos Trabalhadores do Curdistão, fundado na Turquia por Abdullah Öcalan e oriundo da fusão entre independentismo curdo e socialismo revolucionário. A oposição ao Estado Turco se intensificou ainda mais com o golpe militar em 1980, que estabeleceu a dissolução do parlamento e de todos os partidos. Assim, em 1984,o PKK começou a resistir por meio da luta armada, prolongada também no contexto da nova democracia unipartidária, a qual não trouxe melhorias em relação ao reconhecimento dos direitos dos curdos. Além disso, após os ataques de 11 de setembro de 2001, o PKK foi inserido na lista das organizações terroristas pelos EUA, pela UE, pela NATO e pelo Irã, complicando o processo de paz que terá um melhoramento só 
com a declaração de cessar-fogo feita por Öcalan (preso na Turquia desde 1999) em $2013 .^{2}$

Todavia, o lugar onde os curdos conseguiram por em prática concretamente os ideais principais do PKK foi o Curdistão sírio. Já a partir de 2000, os curdos tinham concretizado o confederalismo democrático através da criação de assembleias populares auto-organizadas e, em 2003, fundaram o PYD (Partido da União Democrática), equivalente ao PKK na Síria. Em 2005 Öcalan elaborou mais aprofundadamente o conceito de confederalismo democrático ,que se baseia em uma concepção de liberdade democrática ${ }^{3}$, ecológica e de gênero (Öcalan, 2005), e que se fortaleceu ainda mais com o novo cenário resultante da dissolução do Estado sírio em 2012. Foi em este ano que os curdos declararam a fundação da região autônoma do Rojava (ou Curdistão sírio), composto pelos cantões de Afrin, Jazira e Kobane. Nessa nova realidade política e social, ainda pouco estável e ameaçada por diferentes inimigos, o povo participa direta e ativamente na construção do novo Estado confederativo, que se baseia na representação popular étnica (resolvendo assim uma das questões mais desestabilizadoras da região), e que prevê a luta armada de defesa e libertação por meio da única milícia reconhecida, o YPG, a Unidade de Proteção Popular.

Nessa evolução do independentismo curdo, as mulheres têm desempenhado um papel cada vez mais importante, conquistando a plena igualdade de gênero estabelecida pela Constituição do Rojava de 2013, e a formação, em 2012, do YPJ, ou seja, a Força de Defesa das Mulheres, que tem uma importância fundamental na atual guerra contra o Estado Islâmico. Nos últimos anos, por isso, registrou-se uma atenção sempre maior para a população feminina do Rojava, ativamente engajada tanto politicamente quanto militarmente. Se a fundação do Rojava forneceu a

\footnotetext{
2 O cessar-fogo foi violado pela Turquia em julho 2015.

${ }^{3}$ Aqui o termo democracia não se refere ao sistema parlamentar, mas a participação popular real e efetiva na vida política, social, econômica e cultural da comunidade.
} 
oportunidade para construir de fato a igualdade de gênero, ocorre destacar o papel desempenhado nesse campo tanto pela elaboração teórica do PKK, particularmente do Öcalan, quanto pela participação das mulheres na luta armada desde 1984. Como relatam ArjinAmed e BerfinHesil (1999) ${ }^{4}$, da União das Mulheres Livres do Curdistão, a sociedade curda é tradicionalmente patriarcal $e$ as mulheres não têm um papel importante, pois são submissas à autoridade masculina. Obviamente, a política de negação da identidade curda operada especialmente na Turquia (país onde vive a maioria dos curdos) implicou um natural agravamento da situação feminina: pelo fato de as mulheres não terem tido acesso à educação até os anos setenta, e de elas falarem somente curdo (língua não reconhecida pelo Estado), elas se encontravam totalmente segregadas no espaço privado da vida doméstica, não conseguindo alcançar a liberdade de participar ativamente da vida pública. Ademais, elas sofriam uma dupla violência: por um lado, aquela explicitamente brutal das tropas turcas, as quais empregavam o estupro como arma de guerra para desonrar o povo curdo e marcar o próprio poder; por outro lado, aquela naturalizada e silenciada dos próprios homens curdos que através da humilhação física e mental das mulheres obtinham um espaço mísero de exercício da autoridade e do poder que fundam o patriarcado tradicional e que tinham sido radicalmente negados pela repressão turca (Amed; Hesil, 1999). Assim, com o começo da luta armada em 1984, essas mulheres encontram finalmente um espaço de ação e emancipação até então inimaginável: não tendo nada a perder elas optaram por se dedicar à luta, através da qual poderiam provar a si mesmas e aos próprios homens a capacidade de agir que elas tinham. Desse modo, elas começaram a desnaturalizar a ideia comum de que a mulher fosse sujeita ao domínio masculino. A luta na qual estavam envolvidas, marcada por reivindicações identitárias, as levou a enfrentar

${ }^{4}$ Relatos feitos por Arjin Amed e Berfin Hesil na Conferência sobre a União das mulheres libres do Curdistão, na Itália, em 5 de março de 1999. Cf. http://www.universitadelledonne.it 
simultaneamente o conceito da própria identidade étnica e de mulher: segundo elas, a luta pela emancipação política estava indissoluvelmente conectada à luta pela emancipação social das mulheres. É claro que no começo foram apenas algumas pioneiras a compreender a importância da participação ao movimento de emancipação política numa perspectiva de melhoramento das relações de gênero. Contudo, foi através do exemplo delas que muitas outras fizeram a mesma escolha. A partir disso, foi possível alcançar algumas metas significativas ao longo das últimas décadas: em 1987, foi criada a YJWK, União das Mulheres Patriotas do Curdistão; em 1995, o YJAK, as Tropas de Mulheres Livres do Curdistão; e em 1999, o PJKK, o Partido das Mulheres Livres do Curdistão; por fim, desde o ano 2000, no Curdistão iraquiano, é ativada a Academia das Mulheres Livres, que oferece cursos de formação para militantes homens e mulheres a fim de melhorar as competências políticas e militares numa ótica feminista. Portanto, justamente graças ao confronto direto entre homens e mulheres na luta diária, também os homens chegaram a questionar os seus hábitos. Nesse sentido, foi central a influência exercida por Öcalan, plenamente consciente da importância da participação das mulheres na luta de libertação, proporcionalmente aos homens: em 1998, ele declara a nova ideologia de libertação das mulheres, e em 2013 desenvolve o conceito de Jineoloji. Na sua intervenção na Jineology Conference, de março 2014, em Colônia ${ }^{5}$, GönülKaya, representante das mulheres curdas, afirma que o líder curdo define assim uma "ciência das mulheres" como epistemologia feminina, cujo objetivo seria empreender um caminho para trás, de volta às raízes e à identidade das mulheres e da sociedade que têm sido privadas de suas verdades. Só assim as mulheres podem criar as próprias disciplinas e interpretações para depois compartilhá-las com toda a sociedade, a fim de restaurar o vínculo originário entre conhecimento e liberdade, quebrado por culpa do domínio patriarcal e colonial.

${ }^{5} \mathrm{Em}$ : http://www.iaphitalia.org/gineologia-e-confederalismo-democratico/ 
Porém, as mudanças nas relações de gênero têm dois principais documentos de referência: um é o texto "Liberating Life: Woman's Revolution", uma compilação de textos escritos por Öcalan e publicada em 2013, enquanto o segundo é a Constituição dos Cantões do Rojava, do mesmo ano. No seu texto, o líder socialista destaca como a escravidão da mulher é uma construção histórica que fundamenta de fato qualquer outra escravidão. Ele assinala duas rupturas sexuais principais para a passagem do matriarcado neolítico até o patriarcado atual: a divisão sexual do trabalho, junto com a elaboração do direito de paternidade como direito de propriedade; e o nascimento das religiões monoteístas, que refletem também o advento dos grandes impérios. Assim, o socialismo primitivo que caracterizava o matriarcado originário foi substituído pela centralidade do direito de propriedade e pelo exercício do poder como sinônimo de masculinidade, conceito fundante tanto da ideia de militarismo, quanto aquela de nacionalismo. Porém, o patriarcado se reproduz também na noção de Estado através da ideologia dinástica que fixa a centralidade da família como instituição. Isso esclarece-se pelo paralelismo entre o monopólio do homem sobre a própria família e o monopólio do capital sobre a sociedade. Öcalan chega, assim, a definir capitalismo e nação como exemplos de dominação masculina: essa dominação gerada pela originária violência contra a mulher tornou-se uma construção social totalmente naturalizada, até atuar como verdadeira hegemonia cultural que exclui a mulher de qualquer possibilidade de mudança. Essa lógica de dominação e opressão tem também uma dimensão econômica: a mulher foi, de fato, afastada da economia do trabalho assalariado para ser relegada ao espaço do trabalho doméstico, o qual não tem um valor econômico socialmente reconhecido. Em outras palavras, ela foi constrangida a trabalhar gratuitamente no espaço privado do lar, permitindo a reprodução gratuita da mesma mão-de-obra e o seu sustento. Para sair da hegemonia ideológica da dominação patriarcal e capitalista, central é o papel da mulher: a destruição do Estado capitalista só é possível por meio da transformação da instituição na qual ele está 
baseado, a família patriarcal. Somente substituindo o monopólio masculino com a ideia de liberdade, a família poderá fundar uma sociedade nova e livre: a sociedade socialista. Por isso, Öcalan afirma que o XXI é o século das mulheres, enquanto o papel que uma vez cabia à classe trabalhadora, cabe agora à sororidade entre elas: a realidade dessa opressão é para ele muito mais concreta que outras, especialmente no contexto ex-colonial do Oriente Médio; portanto, a descolonização nacional está vinculada à descolonização da mulher por meio de uma nova epistemologia feminina, ou seja, a Jineoloji (Öcalan, 2013).

O segundo documento fundamental, sobretudo por destacar a dimensão do reconhecimento normativo dos direitos das mulheres na experiência do confederalismo democrático no Rojava, é a Constituição de 2013. ${ }^{6}$ Esse documento concretiza o ideal político da igualdade de gênero a partir de alguns artigos específicos: o art. 23 estabelece a liberdade de gênero como princípio constitucional; o art. 27 reconhece o direito das mulheres à vida política, social, econômica e cultural; o art. 28 estabelece a eliminação de qualquer discriminação de gênero; o art. 87, enfim, estabelece que todos os órgãos institucionais devem consistir de uma porcentagem não inferior a $40 \%$ de ambos os sexos. Portanto, tais instrumentos constitucionais atribuem concretude a todos os ideais do PKK, das e dos militantes curdas e curdos, reconhecendo o papel político central das mulheres $e$ a sua importância crucial na vida do novo país.

\section{O que é gênero?}

A partir dessa breve descrição da peculiar situação das mulheres militantes curdas, é possível desenvolver uma análise desse fenômeno à luz dos principais argumentos concebidos no âmbito da teoria feminista e dos estudos de gênero. A experiência de mudança das relações entre os sexos no Rojava, reconhecida principalmente pela Constituição de 2013, pode ser entendida

${ }^{6} \mathrm{Em}$ https://civiroglu.net/the-constitution-of-the-rojava-cantons/ 
melhor, de fato, por meio de alguns conceitos-chave da elaboração teórica, como gênero, performatividade, sexualização do nacionalismo $e$ interseccionalidade.

As mulheres curdas concretizam, em particular, o questionamento da definição tradicional de gênero feminino no seio da própria sociedade por meio da participação em atividades consideradas tradicionalmente masculinas, como a luta armada $e$ a ação política. Assim, por meio da própria experiência, elas operam uma desnaturalização poderosa do que era a definição compartilhada de mulher, demonstrando concretamente o que já foi teorizado pelo feminismo desde a década de 70, ou seja, a ideia de que o gênero seja uma construção social:

O gênero é um elemento constitutivo de relações sociais baseado nas diferenças percebidas entre os sexos, e o gênero é uma forma primária de significar as relações de poder (Scott, 1990:21).

Todavia essa definição, embora seja essencial no processo de constituição histórica do gênero, não questiona a identidade do sujeito sexuado. Nesse sentido, também o exemplo das mulheres no Rojava, constituído pela aquisição de uma consciência de gênero na evolução que conduz até a autodefinição identitária do sujeito, resulta ofuscado. Em outras palavras, um dos dados principais é que as primeiras mulheres que decidiram participar na luta armada, constituindo um exemplo para muitas outras, fizeram isso como sujeitos negados em busca de autoafirmação $e$ reconhecimento a partir de uma precisa identidade étnica. Só por meio da participação na luta independentista elas conseguem entender que essa luta pela busca de identidade do povo curdo é simultânea à luta pela busca da sua própria identidade enquanto mulheres.

Essa ideia pode ser esclarecida recorrendo à análise de Butler (2003) a respeito do problema de constituição do sujeito, embora ela chegue até um questionamento radicalmente pósestruturalista do sexo biológico que não pode ser sempre 
compartilhado por mulheres envolvidas num contexto social $e$ cultural bem distante da lógica e filosofia ocidentais. Apesar disso, central é a sua teorização do processo de constituição identitária:

Seria errado supor que a discussão sobre a "identidade" deva ser anterior à discussão sobre a identidade de gênero, pela simples razão de que as "pessoas" só se tornam inteligíveis ao adquirir seu gênero em conformidade com padrões reconhecíveis de inteligibilidade do gênero (Butler, 2003:37).

Assim não faz sentido falar de assunção de identidade de gênero por um sujeito, enquanto ele não existe como conceito ontológico primitivo, pois a sua coerência vem de um processo contínuo e instável que pretende recriar a ilusão identitária, ou seja, uma "metafísica da substância" (Butler, 2003:42). Essa substância interna resulta definida por um processo contínuo $e$ repetido que, a partir da noção foucaultiana de focos de poder, transcende o limite do determinismo do filosofo francês, rejeitando o exercício desse poder sobre um sujeito passivo, e reconhecendo na reiteração desse processo de produção/assunção identitária uma possibilidade de alteração e subversão dos discursos $e$ práticas que o estabelecem. Butler define, portanto, o conceito de performatividade "não como 'ato' singular ou intencional, mas, melhor, como prática repetitiva e citacional, por meio da qual o discurso produz o efeito que nomeia" (Butler, 1993:2, tradução minha). ${ }^{7}$ Daí procede a ênfase sobre o valor do corpo e da sua materialização: são as práticas discursivas dos diferentes focos de poder que organizam as fronteiras do corpo, definindo o que é humano e o que não é, segundo um mecanismo que incorpora também o gênero. Mas sendo o próprio corpo a fronteira de percepção do sujeito que assim se constitui, ele oferece um espaço para a mudança, enquanto a experiência corporal direta pode

\footnotetext{
7 No original: "not as a singular or deliberate "act", but, rather, as the reiterative and citational practice by which discourse produces the effects that it names" (Butler, 1993:2).
} 
estar em contradição com as normas sociais $e$ os valores simbólicos produzidos pelo discurso do poder, gerando um curtocircuito que pode levar o sujeito a contestar as normas existentes, até chegar a um processo de ressignificação subversiva dessas fronteiras de sentido.

Em outras palavras, a experiência aparece fundamental para compreender como definições e conceitos tão profundamente naturalizados no seio de qualquer sociedade, podem se revelar na própria dimensão histórico-política. Esse é exatamente o caso das mulheres militantes no Curdistão que, a partir de uma aceitação total da definição tradicional de mulher como destinada a permanecer forçada no espaço privado do próprio lar, cuidando dos seus filhos e se remetendo totalmente à autoridade de um homem, podem entender somente através da luta que tal ideia não está relacionada a nenhuma definição natural. A luta, portanto, não é uma escolha derivante da necessidade de imposição da própria identidade de mulher e de respeito dos seus direitos básicos, pois a adesão das primeiras combatentes tinha como objetivo prioritário a independência e o reconhecimento do povo curdo. Mas, como testemunham Amed e Hesil (1999), a "ressignificação subversiva" (Butler, 1993) dos valores por meio da luta armada, levou as mulheres a se auto-definirem como sujeitomulher, descoberta que gerou também um conflito interno para o reconhecimento da própria identidade dentro do mais amplo movimento curdo de libertação nacional dando prioridade, diferentemente de antes, à tutela dos seus direitos e à mudança das relações entre os sexos. Essa mudança no processo de constituição do sujeito-mulher por meio da concretude da luta ressalta-se nas palavras da militante Destan ${ }^{8}$ :

Eu nunca antes tinha sido acostumada em acreditar que uma mulher poderia ser igual a um homem. Por exemplo,

8 Relato traduzido a partir do original italiano em "Le combattentidello YPJ demoliscono i tabù" em https://www.retekurdistan.it/2014/08/30/le-combattentidelle-ypj-demoliscono-i-tabu/ 
em nossa família o homem sempre foi considerado dominante e eu tinha sempre considerado isso normal $e$ legítimo. Aqui há uma compreensão verdadeira de igualdade e liberdade. Eu entendi nas filas do YPJ que a dominação masculina não era uma parte normal da vida, mas que era contra a ordem natural. Isso criou em mim uma grande sensação de liberdade.

Ademais, para compreender a relevância política e não só conceitual dessa mudança que, além de questionar a dinâmica relacional entre os sexos, permite uma compreensão mais ampla da realidade sociopolítica do Curdistão, é preciso retomar o estudo de gênero como categoria de análise histórica, desenvolvido por Joan Scott (1990). A historiadora parte da definição de gênero efetuada pelo feminismo dos anos '70, para afirmar que, embora se recusasse o determinismo biológico, sublinhando a sua construção social, e embora destacasse o aspecto relacional entre masculino e feminino envolvido no termo, constituía-se como uma definição puramente descritiva. A palavra gênero quer definir a criação social dos papéis atribuídos a homens e mulheres, chegando a libertá-los do vínculo ao sexo biológico; todavia, sem investigar as motivações profundas dessa divisão fundada na vantagem total do homem, esta palavra permanece restrita à área específica das relações entre sexos, perdendo qualquer capacidade explicativa mais ampla das relações políticas e de poder. Portanto, Scott quer libertar tal potencial explicativo, efetuando uma convergência entre a definição teórica de gênero e a sua evolução histórica. É com esse objetivo que ela identifica e critica as três posições teóricas feministas principais naquela altura: a primeira, a crítica feminista ao patriarcado, aparece limitada pela prioridade dada à questão de gênero que se estabelece como não historicizada; a segunda, o feminismo marxista, comete o erro oposto, extinguindo o gênero na dimensão de classe e caindo no determinismo econômico; a terceira, resultante da convergência entre o pós-estruturalismo francês e a teoria das relações objetais das anglo-americanas, 
aparece centrada excessivamente na subjetividade $e$ não historiciza o antagonismo binário entre os sexos (Scott, 1990).

Tendo isso em vista, a autora elabora a própria definição de gênero, a qual tem dois significados complementares. $\mathrm{O}$ primeiro está relacionado com quatro elementos fundamentais: os símbolos culturais, os conceitos normativos, o peso político das instituições e das organizações sociais, e a identidade subjetiva, estabelecendo que "o gênero é, portanto, um meio de decodificar o sentido e de compreender as relações complexas entre diversas formas de interação humana" (Scott, 1990:23). O segundo significado da palavra, por outro lado, resume as reflexões teóricas da autora sobre o gênero como lugar de elaboração do poder: apesar de ter sido sempre excluído da dimensão política, ele se revela imprescindível para entender a relação entre governado $e$ governante. Portanto, se nas dinâmicas caracterizantes de regimes autoritários "os dirigentes que se afirmavam, legitimavam a dominação, a força, a autoridade central e o poder soberano identificando-os ao masculino" (Scott, 1990:25), também o democrático Estado Providência resulta baseado no patriarcado leve do paternalismo protetor.

Portanto, se Butler nos ajuda a esclarecer a ligação entre a produção discursiva sobre o gênero efetuada pelo poder $e$ as suas ligações com o processo de autoafirmação identitária do sujeito, Scott nos permite entender como o próprio termo gênero poderia e teria que ser utilizado como verdadeira ferramenta da análise histórica central na compreensão de conceitos ligados ao estudo das mulheres do Curdistão, como aqueles de sexualização do nacionalismo e o de masculinidade hegemônica, os quais serão desenvolvidos e explicados especialmente pelo feminismo póscolonial. Da mesma forma, a atenção que as duas autoras dão à Foucault, escolhendo desenvolver as próprias análises a partir do conceito foucaultiano de poder, antecipa a formulação sucessiva de ideia de interseccionalidade, que, embora seja ainda muito debatida, destaca como os diferentes focos de poder correspondem a diferentes opressões, que podem se articular entre elas em forma e intensidade variáveis. 


\title{
Gênero e Nacionalismo
}

O estudo de Scott sobre a relevância política do conceito de gênero nos permite compreender quanto esse é um elemento constitutivo das relações sociais entendidas em um sentido mais amplo que o simples confronto entre os sexos, pois "as estruturas hierárquicas baseiam-se em compreensões generalizadas da relação pretensamente natural entre o masculino e o feminino" (Scott, 1990:26). Tal concepção é muito semelhante á ideia desenvolvida por Öcalan (2013) de escravidão feminina como produto de um determinado processo histórico que, através da sua naturalização, constitui um padrão de referência para a estruturação de outros sistemas de escravidão e opressão. A partir daqui, ele destaca o papel do patriarcado no fundamento do Nacionalismo e do Capitalismo:

\begin{abstract}
O Capitalismo e o Estado-Nação representam o macho dominante na sua forma mais institucionalizada. A sociedade capitalista é a continuação e o ápice das velhas sociedades de exploitação. É uma guerra contínua contra a sociedade e as mulheres. Para sintetizar, o capitalismo e o Estado-Nação representam o monopólio do macho tirânico e exploitador (Öcalan, 2013:43, tradução minha). ${ }^{9}$
\end{abstract}

O tema do nacionalismo tem uma importância crucial em relação à luta das mulheres e dos curdos em geral. Esse povo, que tem um próprio conjunto de línguas, uma própria história e uma própria identidade étnica bem definida, tem visto frustradas, depois de $1923^{10}$, as suas aspirações independentistas, sendo espalhado por diferentes outros Estados que nunca reconheceram a sua identidade peculiar. Ademais, os curdos tiveram que

9 No original: "Capitalism and the nation-state represent the dominant male in its most institutionalized form. Capitalist society is the continuation and culmination of all the old exploitative societies. It is a continuous warfare against society and woman. To put it succinctly, capitalism and nation-state are the monopolism of the tyrannical and exploitative male" (Öcalan, 2013:43).

${ }^{10}$ Ano do Tratado de Lausana. 
enfrentar as políticas de nacionalismo agressivo desses mesmos Estados, como testemunham os assassinatos em massa no Iraque, entre 1988 e 1990,e os muitos casos de tortura registrados na Turquia. Esses são exemplos concretos de como o Estado-nação é uma criação baseada na violência exercida sobre o "outro", concebida como atributo da ideia de masculinidade hegemônica. Isso determina que, entre as vítimas de nacionalismo agressivo $e$ "masculino", as mulheres são sempre as mais vulneráveis. Veena Das (1995), na sua análise da formação dos Estados da Índia e do Paquistão, em 1947, por meio do rapto das mulheres, destaca alguns conceitos muito relevantes para a ideia do paralelismo entre contrato social e contrato sexual desenvolvida por Öcalan (2013). A partir do contexto indiano, ela identifica as duas virtudes socialmente principais, ou seja honra para homens e pureza para mulheres. Em particular, a honra do homem como chefe da família resulta ser vinculada à preservação da pureza da própria mulher, pois é ela que, enquanto mãe, assegura a pureza de sangue da própria estirpe. Portanto a família se constitui como núcleo essencial do mesmo Estado: "o compromisso do Estado para a reabilitação de mulheres é o reconhecimento da autoridade do pai como fundação necessária da autoridade do mesmo estado" (Das, 2007:34, tradução minha). ${ }^{11} \mathrm{O}$ contrato social que funda o Estado, assim, deriva do consentimento entre homens, chefes de família, de modo que apareça definitivamente estabelecida a ligação entre esse contrato e o contrato sexual.

Há aqui dois pensamentos. O primeiro é que, para ser cidadão do Estado, você deve ser chefe da família; o segundo é que você tem que conhecer para quem você deveria morrer. Para as mulheres, o dever como cidades

${ }^{11}$ No original: "the state's commitment to the recovery of women is the acknowledgment of the authority of the father as the necessary foundation of the authority for the state" (Das, 2007:34). 
está cunfundido com os seus deveres para os seus maridos.

(Das, 2007:35, tradução minha). ${ }^{12}$

O Estado, nesse sentido, define-se como patriarca: no contrato social, a mulher é a ferramenta do homem para experimentar a sociabilidade do sexo. Ela lhe permite ser pai $e$ marido, exercer aquela autoridade familiar que é pré-requisito fundamental para que ele seja reconhecido como cidadão. Desse modo, uma vez que o Estado é definido como "masculino", parece mais fácil compreender "the question of national honour" (Das, 1995:66), que produz como consequências tanto a hipersexualização do "outro", ou seja o inimigo, tanto a prática do estupro como arma de guerra. A antropóloga indiana, através da observação do conflito entre Hindu e Sikhs, em 1984, exemplifica como a sexualização do nacionalismo determina um contraste entre grupos étnicos rivais fundado na oposição simbólica entre sexo masculino e sexo feminino. Cada grupo pretende assumir o papel de masculino hegemônico por meio do exercício da violência sobre o rival, o qual resulta assim inferiorizado enquanto feminilizado (Das, 2007).

Isso leva automaticamente a ressaltar a função crucial da violência nesse processo de feminilização e dominação do "outro". Mas a violação deste último, além de ser uma ferramenta ideológica determinante na construção da identidade nacional, tem também uma repercussão prática na adoção do estupro como arma de guerra. Para garantir a aniquilação e a sujeição do inimigo é preciso desonrar a sua raça, estuprando as suas mulheres: "em todos esses discursos notamos que as mulheres são redefinidas como objetos semióticos sobre os quais a ação do

\footnotetext{
${ }^{12}$ No original: "There are two thoughts here. The first is that to be a citizen of the state, you must be the head of a household; the second is that you must know for whom you ought to die. For the woman, the duty as citizen is confounded with her duty to her husband' (Das, 2007:35).
} 
Estado pode ser inscrevida" (Das, 1995:70, tradução minha)..$^{13}$ Podese afirmar, em vista disso, que existe uma genderization da violência no processo de constituição do Estado-nação, enquanto ela está exercida basicamente sobre as mulheres: é o corpo da mulher o campo de batalha privilegiado dos conflitos nacionalistas. Isso resulta ser ainda mais claro quando se considera que geralmente os homens, cujas masculinidade $e$ virilidade são negadas e castradas por outros homens, precisam reafirmá-las por meio da violência contra as próprias mulheres. Só assim, como em qualquer sociedade baseada no patriarcado, eles podem preservar uma parte, embora mínima, da própria masculinidade hegemônica. Essa dupla vulnerabilidade é ressaltada pelas palavras de Hamed e Hesil (1999), justamente em relação à condição das mulheres curdas, antecedente à participação delas na luta armada.

Portanto, a genderization da violência determina a definição da mulher como vítima, pois é ela que experimenta a dor prioritariamente em relação ao homem:

Parece que há um contraste entre dois modos diferentes para considerar a dor, como eles foram formulados dentro da tradição sociológica clássica. De acordo com a primeira elaboração, dor é o modo com o qual a sociedade estabelece sua propriedade nos indivíduos. De acordo com a segunda elaboração, dor é a ferramenta individual pela qual uma culpa histórica feita a uma pessoa pode ser representada, assumindo às vezes a forma da descrição dos sintomas individuais e, outras vezes, a forma da memória marcada no corpo (Das, 1995:176, tradução minha). ${ }^{14}$

\footnotetext{
${ }^{13}$ No original: "In all this discussion we see that women are being redefined as semiotic objects on which the actions of the state are to be inscribed" (Das, 1995:70).

${ }^{14}$ No original: "There seems to me a contrast between two different ways of looking at pain, as these have been formulated within classical sociological traditions. According to the first formulation, pain is the medium through which society establishes its ownership over individuals. According to the second, pain is the medium available to an individual through which a historical wrong done to a
} 
Esse segundo sentido mencionado por Das estabelece uma ligação profunda com a memória, pois a experiência vivida da dor permanece marcada no corpo, gerando uma forma de memória física, corporizada. Sendo assim, muitas vezes essa mesma memória física não alcança uma dimensão coletiva, enquanto a experiência pessoal e corporizada da violência parece à vítima como algo extremamente individual; algo tão devastador que aniquila a linguagem, fazendo com que ela nem consiga elaborar a própria dor através das palavras para conseguir comunicá-la. Isso implica que muitas vezes as vítimas, não tendo meios linguísticos para descrever o próprio sofrimento, não conseguem reconhecê-lo e identificá-lo. "Daqui deriva a habilidade das vítimas de se organizar para entender o que tinha acontecido e par pedir adquirir justiça por elas mesmas" (Das, 1995:204, tradução minha). ${ }^{15}$ É a comunicação da vivência da dor que pode transcender o nível pessoal até chegar à compreensão da existência de uma situação compartilhada que produz o questionamento das causas últimas determinantes dessa mesma situação. "Se a tentativa de nomear a violência representa um desafio é porque essa tentativa tem limites políticos amplos, e não só porque o idioma vacila frente à violência" (Das, 2007:205, tradução minha). ${ }^{16}$ Isto é, a violência política, como aquela do nacionalismo, envolve um outro problema além da falácia linguística: as manipulações $e$ as estruturações de significado realizadas pelo poder que alteram a percepção individual das mesmas vítimas. A consciência da dor, então, parece ser muito relacionada, segundo Das (1995), ao compartilhamento da

person can be represented, taking sometimes the form of describing individual symptoms and at other times the form of a memory inscribed on the body" (Das, 1995:176).

${ }^{15}$ No original: "Here the ability of the victims to organize themselves, both to understand what has happened and to demand to secure justice for themselves" (Das, 1995:204).

${ }^{16}$ No original: "If the process of naming the violence presents a challenge, it is because such naming has large political stakes, and not only because language falters in the face of violence" (Das, 2007:205). 
linguagem do corpo, que pode expressar essa própria experiência transcendendo os limites da linguagem.

Essa centralidade da experiência, pelo fato de ser algo extremamente pessoal, pode gerar reações muito diferentes, entre elas, obriga a sair do binarismo entre passividade e resistência para destacar a importância do trabalho efetuado pelas mulheres ao nível da vida cotidiana, através de uma reelaboração da dor no dia a dia. Em relação a isso, o caso das mulheres curdas constitui uma diferença: elas chegam a compartilhar a própria vivência de dor, além da pura reelaboração na cotidianidade, pois algo inesperado estoura na própria vida, ou seja, o começo da luta armada. É esse evento que cria uma ruptura na dimensão da cotidianidade para instituir um espaço-tempo novo e diferente, no qual elas encontram o lugar $e$ as modalidades para expressar a própria vivência. A luta, nesse sentido, abre novos caminhos $e$ possibilidades $e$ permite às militantes sair do isolamento do ambiente doméstico, se aproximar uma da outra e compartilhar as próprias histórias, chegando à consciência das causas políticas $e$ sociais do próprio sofrimento. Como experiência comum $e$ inovadora, a luta leva as mulheres a entender que juntas elas podem externara própria voz, gritar e reivindicar os próprios direitos para gerar uma emancipação política e social efetiva. No relato da militante Destan:

as YPG mudaram a percepção de que as mulheres são fracas e não podem fazer nada. Estudei sete anos na escola, depois me levaram embora. Se não fosse para a Revolução, eu provavelmente teria me casado e seria uma mãe solteira (tradução minha). ${ }^{17}$

\footnotetext{
${ }^{17}$ Relato traduzido a partir do original italiano em "Le combattentidello YPJ demoliscono i tabù"em https://www.retekurdistan.it/2014/08/30/le-combattentidelle-ypj-demoliscono-i-tabu/
} 


\section{Etnicidade e gênero no Curdistão}

Se nós consideramos o colonialismo não só em termos de nação e país, mas também em termos de grupos de pessoas, podemos definir as mulheres como o grupo colonizado mais antigo. De facto, nenhum outro ser social experimentou uma forma tão completa de colonialismo, tanto na alma quanto no corpo. Deve ser bem intendido que a mulher está forçada em uma colônia sem fronteiras identificáveis claramente (Öcalan, 2013:56, tradução minha). ${ }^{18}$

Com essas palavras, Öcalan introduz outra questão muito relevante em relação ao assunto tratado neste trabalho, ou seja, o paralelismo entre domínio masculino sobre a mulher e domínio colonial que, por sua vez, está relacionado ao capitalismo. Ele aponta como a própria lógica de dominação é estruturada nos três eixos teóricos de gênero, classe e nacionalidade, entre os quais, todavia, a opressão de gênero, por meio da sua naturalização originária, parece fundar as outras duas.

Então, antes de analisar a categoria de classe, devemos ser capazes de analisar a sororidade entre mulheres - isto nos fará capazes de formar um conhecimento mais claro das categorias de classe e nacionalidade (Öcalan, 2013:52, tradução minha). ${ }^{19}$

Assim, o líder curdo reforça a ideia de que a lógica de domínio pode se concretizar em situações práticas diferentes e não excludentes, que têm que ser enfrentadas em conjunto até a

\footnotetext{
${ }^{18}$ No original: "If we see colonialism not only in terms of nation and country but also in terms of groups of people, we can define woman as the oldest colonised group. Indeed, in both soul and body, no other social being has experienced such complete colonialism. It must be well understand too that woman is kept in a colony with no easily identifiable borders" (Öcalan, 2013:56).

${ }^{19}$ No original: "So, before we can analyze class, we must be able to analyze the sisterhood of women- this will enable us to form a much clearer understanding of the issues of class and nationality" (Öcalan, 2013:52).
} 
derrota do verdadeiro "nó" problemático que as funda, que é essa própria lógica.

Como acima apontado, o assunto do Colonialismo é central na questão dos curdos, um povo que nunca conseguiu ser independente e que foi governado por outros Estados através de práticas coloniais, como a negação da identidade ou o estupro de guerra. Nesse sentido, cabe destacar a análise desenvolvida para McClintock (2010) e retomada por Da Silva Noleto (2015) sobre as conexões entre raça, gênero e classe na articulação do sentido mais profundo de nacionalidade, pois a principal causa de persecução dos curdos e de negação da sua identidade é precisamente eles encarnarem fisicamente o "outro", a diferença a respeito dos valores sociais, culturais e políticos dos países em que foram constrangidos a viver por meio do acordo colonial de 1923. McClintock demarca essa ligação entre marcadores sociais da diferença de uma forma muito clara:

Aqui, então, gênero não é só uma questão de sexualidade, mas também uma questão de subordinação do trabalho $e$ pilhagem imperial; raça não é só uma questão de cor da pele, mas também uma questão de força de trabalho, incubada pelo gênero. Apresso-me a acrescentar que não quero implicar que esses domínios são redutíveis ou idénticos entre si; em vez disso, existem relações íntimas, recíprocas e contraditórias (McClintock, 2010:19-20).

A partir disso, Da Silva Noleto afirma que:

a autora perece convicta de que o imperialismo não foi organizado em torno de uma única categoria social privilegiada (raça, classe, gênero ou sexualidade), mas foi engendrado a partir do cruzamento de todos os mecanismos de produção de diferença com vista a tornar explícitas e naturalizadas as fronteiras entre dominantes $e$ dominados (Da Silva Noleto, 2015:125). 
Para ele, qualquer reflexão intelectual que tenha como objetivo a análise das relações de poder precisa se fundar "numa crítica da produção de diferença com base na articulação dos eixos de raça, classe, gênero e sexualidade" (Da Silva Noleto, 2015:125).

Portanto, se a importância da dimensão de gênero no processo de constituição nacional tinha sido já esclarecida $e$ documentada por meio da análise de Das (1995, 2007), os conceitos formulados por McClintock (2010) e Da Silva Noleto (2015), encontrados também nas palavras de Öcalan, problematizam ainda mais a questão, fazendo com que enfrentemos simultaneamente vários outros marcadores de diferença como raça e classe, e nos obrigando, ademais, a explanar o próprio sentido teórico de palavras como raça $e$ diferença.

Em relação à questão de raça $e$ às suas ligações com os conceitos de etnicidade, sexo e gênero, deve-se ressaltar o aporte de Stolcke (1991) focado no questionamento do binarismo entre natureza e cultura, que funda todas essas definições categóricas:

Quero examinar, contudo, o modo como, na sociedade de classes, certas desigualdades socialmente relevantes são marcadas e legitimadas por uma explicação que as representa como tendo raízes nas diferenças naturais (Stolcke, 1991:101).

A partir do conceito de gênero como construção social fundada no sexo por um processo que não consegue chegar até a recusa do seu determinismo biológico, Stolcke aponta como a ideia semelhante de etnicidade enquanto construção social baseada numa concepção biológica de raça seja muito mais dificilmente aceitável. Se a naturalização da raça teve um papel básico no racismo científico do século XVIII para fornecer uma legitimação ideológica à escravidão, nos anos seguintes, com as demonstrações científicas de que não existem raças entre os seres humanos, e ainda mais por causa do horror gerado após a Segunda Guerra Mundial pelos crimes do Holocausto, o termo 
raça foi substituído pelo termo etnicidade: "a intenção era enfatizar, que os grupos humanos eram um fenômeno histórico $e$ cultural" (Stolcke, 1991:106). Todavia essa nova contextualização sociocultural não operou colocando no mesmo nível as várias culturas, mas criou novas hierarquias através de um determinismo cultural que acabou substituindo o precedente determinismo biológico: "os traços culturais são naturalizados ou estão conjugados com critérios supostamente biológicos sob o título de discriminação racial" (Stolcke, 1991:108). Todavia, sendo o objetivo da autora sair do binarismo entre natureza e cultura, ela destaca a necessidade de historicizar também as categorias consideradas naturais, e que, na realidade, fundam a desigualdade capitalista:

as diferenças de sexo, não menos que as de raça, foram $e$ continuam a ser ideologicamente identificadas como fatos biológicos socialmente significativos na sociedade de classes e são construídas e legitimadas por se basearem nos supostos fatos biológicos das diferenças de raça e sexo. A característica decisiva da sociedade de classes a esse respeito é uma tendência geral a naturalizar a desigualdade social. Essa naturalização constitui, com efeito, um procedimento ideológico fundamental na sociedade de classes para superar as contradições que lhe são inerentes (Stolcke, 1991:110).

Dessa forma, o conceito de raça, ou seja, o seu sentido, assim como de sexo, é produto do contexto social no qual é elaborado. No âmbito da realidade curda, essa lógica de domínio baseada na naturalização das diferenças está estruturada, por Öcalan, a partir de uma perspectiva diferente. Se para Stolcke é a sociedade de classe a estabelecer a naturalização da desigualdade racial e sexual para legitimar a desigualdade social, de acordo com o líder curdo é o padrão originário da dominação masculina sobre a mulher a estabelecer a lógica que se reflete nas outras opressões. Apesar disso, os dois convergem teoricamente no que diz respeito à necessidade de suprimir a sociedade de classes capitalista para criar uma nova realidade econômica política e social, na qual as 
categorias que fundam as diferentes formas de desigualdade não tenham mais sentido: "Então, matar o macho dominante é um princípio fundamental do socialismo. matar o poder significa isto: matar o domínio, a desigualdade e a intolerância unilaterais" (Öcalan, 2013:51, tradução minha). ${ }^{20}$

Enfim, sendo essas categorias um produto histórico-social, ou seja, contextual, parece ilusório acreditar que o poder exerça a mesma forma de dominação em todas as situações, do mesmo modo. Embora a lógica fundante seja a mesma, as formas nas quais essas categorias se estruturam variam muito entre elas e em relação aos sujeitos que são por elas determinados. Isto é, a maioria dos indivíduos que vive no mundo marcado pelo capitalismo vive a própria opressão, mas cada um a experimenta numa forma diferente e dependente das várias relações de poder que articulam a sua identidade e a sua vida cotidiana. Uma mulher branca experimenta uma discriminação de gênero diferente da discriminação de raça de um homem negro, assim como este último resulta discriminado diferentemente de uma mulher negra. Essa heterogeneidade de experiências e situações leva necessariamente a enfrentarmos "a problemática da subjetividade e da identidade para compreender a dinâmica de poder da diferenciação social" (Brah, 2006:332). O assunto da diferença no processo de estruturação do sujeito político chega a ser, desse modo, o foco da questão, nos conduzindo a questionar o essencialismo que muitas vezes nos permite delinear um sujeito político homogêneo e não problematizado (como pode ser $o$ negro, ou a mulher), que, embora torne mais fácil o nosso estudo, nos afasta da realidade dos fatos.

Portanto Brah, a partir da crítica do etnicismo do termo negro, que reduz as várias experiências de grupos diferentes a um sentido especificamente cultural fundado numa suposta coerência interna a essa categoria, mas também a partir da crítica do

\footnotetext{
${ }^{20}$ No original: "Indeed to kill the dominant male is the fundamental principle of socialism. This is what killing power means: to kill the one-sided domination, the inequality and intolerance" (Öcalan, 2013:51).
} 
universalismo do sujeito mulher baseado no padrão de referência classicamente ocidental do feminismo europeu, sublinha a importância da noção de articulação:

De maneira semelhante, Laclau e Mouffe notam que articulação é uma prática e não o nome de um dado complexo relacional; isto é, articulação não é simples junção de duas ou mais entidades discretas. Melhor, é um movimento transformador de configurações relacionais. A procura por grandes teorias que especifiquem as interconexões entre racismo, gênero e classe foi bem menos do que produtiva. Melhor construí-las como relações historicamente contingentes e específicas a determinado contexto (Brah, 2006:353).

As diferentes categorias que articulam a desigualdade, não operam através de uma divisão geométrica de espaços fixos e claramente definidos de opressão de um tipo ou de outro, enquanto devem-se entender no próprio aspecto mais dinâmico $e$ relacional, o qual nos impede de cair na armadilha do essencialismo. Contextualizando racismo e sexismo nas suas causas relacionais, ademais, é possível sair do isolamento teóricoconceitual das lutas e encontrar na concretude delas uma opção de mudança eficaz.

Por isso Brah define quatro tipos de diferenças: primeiro a diferença como experiência, enquanto a vida diária reflete a constituição social, com base na ideia de que o pessoal é político. Assim, a autora não exclui a possibilidade de uma ação comum, pois a diferença pode ser definida num nível individual, assim como num nível coletivo, em interação mútua. Segundo, a diferença como relação social, a qual possui uma sistematicidade que transcende a contingência do pessoal, juntando instituições, plano histórico-material e práticas culturais. Terceiro, a diferença como subjetividade, baseada na ideia de sujeito produzido através do discurso, questiona o universalismo do sujeito europeu $e$, recorrendo à psicanálise, destaca como a formação do próprio sujeito seja articulada no plano social assim como no plano 
individual. Por fim, a diferença como identidade, pelo fato de se basear numa concepção de identidade como multiplicidade relacional mais do que algo fixo e singular, constitui-se como luta contínua para fornecer um pouco mais de estabilidade à subjetividade. Embora contextual e mutável, essa identidade, que por isso é definida a nível coletivo, pode estabelecer parcialmente a subjetividade (Brah, 2006).

Essa prioridade ao conceito de diferença e à crítica do essencialismo feito por $\operatorname{Brah}(2006)$ acaba por se relacionar estreitamente com a crítica da naturalização das categorias feita por Stolcke (1991), a qual recusa esse próprio essencialismo. Nessa perspectiva cabe apresentar a noção de saberes localizados desenvolvida por Haraway (1995). Ela, deslocando esse próprio argumento até um nível mais epistemológico, pretende recusar qualquer reivindicação de objetividade científica, demonstrando a "especificidade histórica radical e, portanto, contestabilidade, de todas as camadas da cebola das construções científicas $e$ tecnológicas" (Haraway,1995:13). Mas isso não pode levar nem a um construcionismo radical que, negando qualquer forma de objetividade e realidade, limita a ação política, nem a um "empiricismo feminista" (Haraway,1995:15) que resulte vinculado à legitimação da objetividade. Portanto, ela retoma a noção de ciência sucessora de Harding:

creio que o meu e o "nosso" problema é como ter, simultaneamente, uma explicação da contingência histórica radical sobre todo conhecimento postulado $e$ todos os sujeitos cognoscentes, uma prática crítica de reconhecimento de nossas próprias "tecnologias semióticas" para a construção de sentido, e um compromisso a sério com explicações fiéis de um mundo "real", um mundo que possa ser parcialmente compartilhado $e$ amistoso em relação a projetos terrestres de liberdade finita, abundância material adequada, sofrimento reduzido e felicidade limitada (Haraway, 1995:15-16). 
É a partir desse conceito, o qual pressupõe a capacidade de tradução das várias formas de conhecimento existentes no mundo, que é possível chegar à desconstrução da dominação epistemológica da objetividade científica e à sua substituição por aqueles que Haraway (1995) define "saberes localizados". Fundamental nesse processo é a definição de visão, a qual não pode ser mais baseada numa ilusão de infinidade, mas tem que reconhecer a própria dimensão parcial e corporificada, ou seja, localizada, enquanto exatamente dependente da experiência subjetiva a partir da qual o sujeito atua. A consciência desse processo de conhecimento tem duas consequências fundamentais: por um lado, perdendo qualquer pretensão de se constituir como verdades absolutas, esses saberes localizados determinam uma escolha politica e eticamente responsável, por outro lado, sendo cada visão parcial e localizada, é preciso chegar a uma conexão entre elas para termos um conhecimento mais adequado da realidade. Ou seja, cada sujeito, sendo multidimensional e não homogêneo, tem visões e perspectivas que variam nas diferentes situações que vivencia; nesse sentido, o feminismo tem um papel epistemologicamente central:

O feminismo ama outra ciência: a ciência e a política da interpretação, da tradução, do gaguejar e do parcialmente compreendido. O feminismo tem a ver com as ciências dos sujeitos múltiplos com (pelo menos) visão dupla. O feminismo tem a ver com uma visão crítica, consequente com um posicionamento crítico num espaço social não homogêneo e marcado pelo gênero (Haraway, 1995:31).

Mas o papel do Feminismo transcende o nível epistemológico para alcançar a ação prática que leva a mudança efetiva pois, rejeitando a ideia de um objeto passivo totalmente determinado pelo poder (como por muito tempo foi considerada a mulher), ele questiona os seus fundamentos, o binarismo ocidental entre sujeito e objeto, restabelecendo a agência deste último. Enfim, a análise de Haraway, sendo focada na desconstrução epistemológica da noção de verdade científica, resulta ter muito 
em comum com a crítica desenvolvida por Öcalan contra a lógica da dominação: os dois estruturam um discurso no qual a dimensão epistemológica parece determinante e ressaltam como a mulher tem um papel determinante na mudança desse paradigma científico e cultural (lembrando da noção de jineoloji).

Portanto, os estudos aqui relatados sobre o assunto dos marcadores sociais da diferença e das relações existentes entre eles estão ligados à questão do povo curdo basicamente pela problematização que eles operam na constituição da identidade curda. Enquanto povo sem pátria, os curdos continuaram sempre sendo colonizados e, como Öcalan e os depoimentos das mulheres curdas destacam, essa situação tem um peso ainda maior em relação ao sexo feminino. O líder curdo ressalta essa fundamental articulação entre raça e gênero na sua crítica ao eurocentrismo do feminismo teórico dominante e na necessidade de que o processo de libertação seja conduzido pelas mulheres curdas em primeira pessoa, sem a ajuda dos homens ou das mulheres que vivem em condições radicalmente diferentes, porque só isso pode garantir o sucesso da revolução curda: "Womens' revolution is a revolution within a revolution" (Öcalan, 2013:59).

\section{Conclusões}

Esta exposição tem como objetivo primário entender como é possível destacar a importância de experiência de luta e resistência das mulheres militantes curdas na dinâmica das relações de gênero da sociedade a que pertencem. Embora seja claro que nem todas as mulheres curdas tenham escolhido o caminho da luta armada, pois, como foi evidenciado na primeira parte deste artigo, é bem difícil pensar os curdos como um grupo homogêneo, quero destacar como a participação das primeiras pioneiras na luta forneceu um exemplo concreto para as demais. Assim elas propagaram uma outra ideia de "mulher" e definiram a base constitutiva das seguintes etapas, como a criação do exército feminino, das academias para a promoção do feminismo até 
chegar ao reconhecimento formal dos direitos das mulheres na Constituição do Rojava de 2013.

Central nesse caso é a concretude dessa experiência, que às vezes parece ser limitada por um estudo baseado num recorte conceitual elaborado em contextos bem diferentes daquele curdo. Todavia as referências às diferentes autoras $e$ autores apresentados neste texto visam explicar a partir de uma perspectiva teórica e conceitual as dinâmicas geradas na prática por estas mulheres. Nesse sentido foi atribuída grande importância à análise efetuada por Öcalan: é fundamental entender que, embora ele seja o líder político curdo mais conhecido e apoiado, através da sua obra ele (enquanto homem) não quer se apropriar da luta feminina e geri-la. Portanto, ele enfatiza o crucial de um processo já iniciado em forma autônoma pelas mulheres e explora a sua própria influência para que também os homens curdos possam compreender a relevância dessa participação. Além disso, nos últimos anos, desde que as mulheres conseguiram ter uma maior visibilidade também em nível internacional, elas têm podido externar sua voz e falar por elas mesmas, esclarecendo as próprias prioridades e necessidades; isso é evidente entre as mulheres do exército do YPJ que recentemente tem participado de muitos atos e debates no mundo todo para socializar a própria experiência de forma autônoma e direta.

Atualmente, na verdade, a imagem das combatentes é difundida cada vez mais por causa do seu papel na luta contra o Estado Islâmico na área da Síria. Os curdos do Rojava são ativos desde 2012 para bloquear o avanço dos fundamentalistas de Daesh e a participação feminina nesse conflito marca algumas reflexões relevantes na ótica dos estudos de gênero e póscoloniais. Sendo os próprios curdos muçulmanos, essa luta quebra a imagem estereotipada da mulher islâmica submissa e que precisa do modelo do feminismo europeu para mudar a própria situação, acentuando o poder de ação que ela tem sem ter necessidade de sair do próprio contexto cultural e religioso. Ademais, essa mesma circunstância reverte também um outro estereótipo ainda muito enraizado na cultura ocidental, ou seja, a 
ideia de homogeneidade e univocidade do mundo islâmico, como já tinha eficazmente demonstrado Said (1999).

Esse protagonismo feminino tem sido muito explorado pela mídia da Europa, que o limitou apenas à luta contra o Estado Islâmico, deixando na sombra as mudanças sociais e políticas envolvidas no conceito de confederalismo democrático que está na base da experiência no Rojava, assim como a forte repressão atuada pela Turquia (fiel aliada europeia) no Curdistão. ${ }^{21} \mathrm{~A}$ hipocrisia do Ocidente é claramente visível no contraste entre discursos públicos e praxis. embora as e os combatentes curdas/os sejam os únicos a enfrentar diretamente o Estado Islâmico, ou seja, o primeiro inimigo do Ocidente de nossa época, eles permanecem ainda na lista de organizações terroristas de 2001 e a Constituição de Rojava de 2013 ainda falta do reconhecimento ocidental.

Enfim, as questões principais envolvidas tanto no independentismo curdo quanto no combate contra Daesh estão em pleno curso de desenvolvimento e por isso é ainda impossível entender quais serão as consequências. $\mathrm{O}$ que este trabalho quer destacar é a centralidade do protagonismo feminino nesse quadro complexo, o qual, por sua vez, não pode ser isolado das mudanças políticas e sociais que a Constituição do Rojava reconheceu em 2013. O que eu quero enfatizar é que os progressos dos e das curdos/as no campo das relações de gênero seriam impensáveis em um contexto social e político diferente. A luta contra o machismo e a violência de gênero é um componente essencial do modelo do confederalismo democrático: é somente dentro desse modelo radicalmente "outro" da sociedade que podemos entender plenamente o protagonismo feminino das mulheres curdas e seu peso ao nível político, social e cultural.

\footnotetext{
${ }^{21}$ No âmbito da luta contra o Estado Islâmico, a Turquia bombardeou massivamente as posições do PKK na Síria, em julho 2015, rompendo assim o cessar-fogo declarado por Öcalan em 2013.
} 
Figura 1 - Distribuição do povo curdo

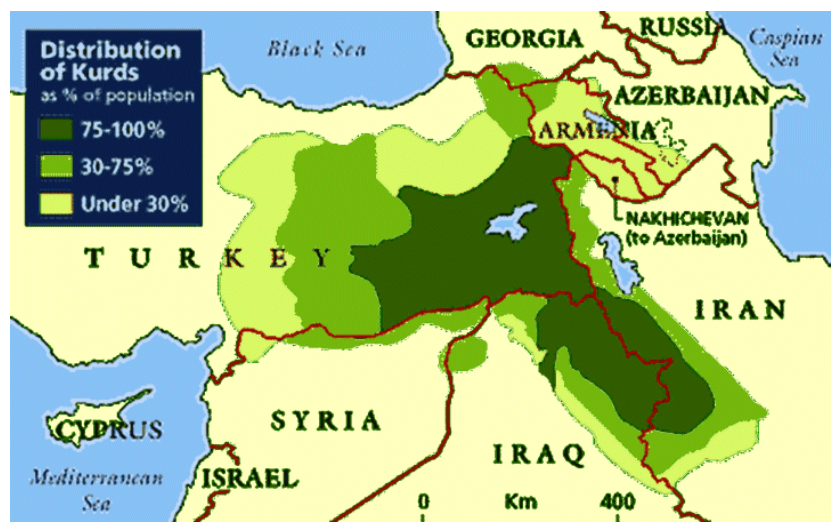

Fonte: International Press Agency [https:/www.pressenza.com/2015/06/kurds-a-common-issue-for-iranturkey/ - acesso em: 31 jul 2019].

\section{Figura 2 - Mapa do Rojava em 2014}

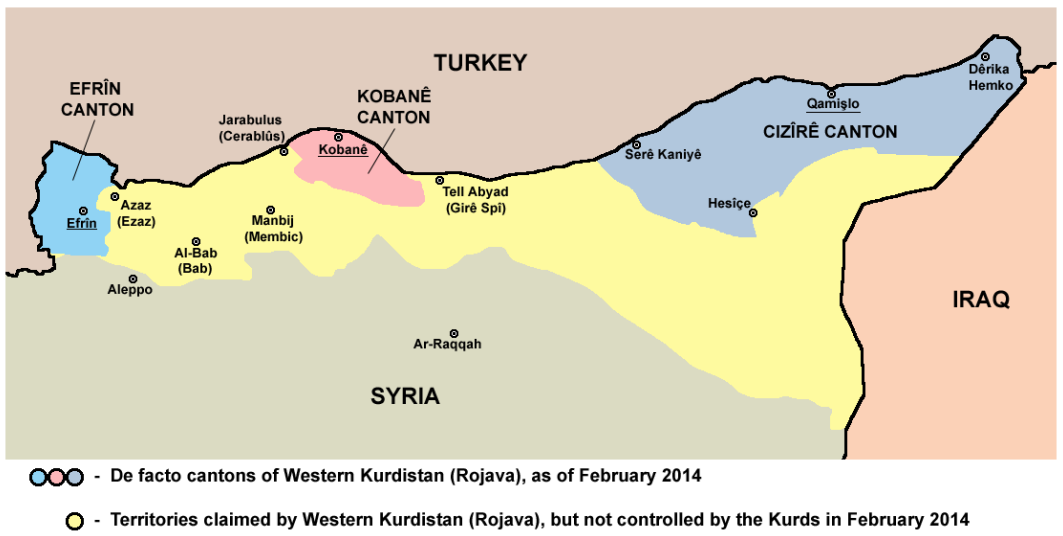

Fonte : Near East News Agency (Nena News), Agenzia Stampa Vicino Oriente [http://nena-news.it/siria-curdi-non-puntiamo-allo-stato-ma-alla-democrazia/ acesso em: 31 jul 2019]. 


\section{Referências bibliográficas}

BRAH, Avtar. Diferença, diversidade, diferenciação. cadernos pagu (26), Campinas, SP, Núcleo de Estudos de Gênero-Pagu/Unicamp, 2006, pp.329-276.

BuTLER, Judith. Bodies that matter. New York, Routledge, 1993.

ButLen, Judith. Problemas de Gênero. Rio de Janeiro, Civilização Brasileira, 2003.

DA SILVA NolETO, Rafael. Comunidades sexualizadas: articulando raça, gênero e sexualidade na construção de nações. In: CANCELA, Cristina Donza; MoutinHO, Laura; SIMÕES, Júlio Assis (org.).Raça, etnicidade, sexualidade e gênero em perspectiva comparada. São Paulo, Editora Terceiro Nome,2015, pp.121-141.

DAS, Veena. Critical Events: An Anthropological Perspective on Contemporary India. New Delhi, Oxford University Press, 1995.

DAS, Veena. Life and Words: Violence and the descent into the ordinary". Berkeley, University of California Press, 2007.

HARAWAY, Donna. Saberes Localizados. cadernos pagu (5), Campinas, SP, Núcleo de Estudos de Gênero-Pagu/Unicamp, 1995, pp.07-41.

MCCLINTOCK, Anne.Couro Imperial; raça, gênero e sexualidade no embate colonial. Campinas,Editora da Unicamp, 2010.

ÖCALAN, Abdullah.Democratic Confederalism, Cologne, International Initiative Edition, 2005.

ÖCALAN, Abdullah.Liberating life: Woman's Revolution. Cologne, International Initiative Edition, 2013.

SAID, Edward. Orientalismo. Milano, Feltrinelli, 1999.

SCOTT, Joan. Gênero, uma categoria útil de análise histórica. Educação e Realidade, 16 (2), Porto Alegre, jul-dez 1990, pp.5-22.

STOLCKE, Verena. Sexo está para gênero assim como raça para etnicidade?. Estudos Afro-Asiáticos (20), 1991, pp.101-119. 
cadernos pagu (56), 2019:e195611 Militância política e relações de gênero: o caso das mulheres militantes no Curdistão

\section{Webgrafia}

http://civiroglu.net/

www.retekurdistan.it

www.universitàdelledonne.it

www.ukionlus.com

www.iaphitlia.org 